\title{
EVALUATION OF WEAR OF MILLING CUTTERS FOR DRILLING OF NAIL HOLES USED FOR OSTEOSYNTHESIS OF LONG BONES OF LOWER LIMBS
}

\author{
KUBÁŠOVÁ Kristýna ${ }^{1}$, SEDLÁČEK Radek ${ }^{1}$, HORNÝ Lukášs \\ ${ }^{1}$ Czech Technical University in Prague, Faculty of Mechanical Engineering, Department of Mechanics, \\ Biomechanics and Mechatronics, Technická 4, 16000 Praha 6, Czech Republic, e-mail: \\ Kristyna.Kubasova@fs.cvut.cz, Radek.Sedlacek@fs.cvut.cz, Lukas.Horny@fs.cvut.cz
}

\begin{abstract}
This paper deals with wear of intramedullary milling cutters for the drilling of nail holes used for osteosynthesis of lower limbs long bones. After the physician's complaints about the increasing resistance and total change of its properties that are caused by the reuse the instrument, we have designed a suitable methodology to verify and quantify this problem. The experiment was carried out on three types of milling cutters, differing in their diameter. Using statistical tests, we compared pressure force and torque before and after wear.
\end{abstract}

KEYWORDS: milling cutters, wear, methodology; experiment

\section{Introduction}

In the treatment of long bone fractures, such as tibia, common approach is the implantation of a nail, who supports the healing bone tissue. Bone osteosynthesis occurs after reinforcing with the nail, that passes through the medullary cavity in the length of the bone. An important factor that affects the healing process the wound in the bone caused by the cut when we need to get the nail through the bone. An important technological aspect of nail implantation is the removal of tissue during drilling (respective milling) of the cavity. One of the problems to be addressed is the objectification of the wear rate of the drilling instrument [1].

The main problem and initiative for this study was the fact that doctors (orthopedics and surgeons) are feeling increasing resistance during repeating usage of the instrument. The presented work tries to solve the decreasing quality of intramedullary milling cutters for the drilling of nail holes used for the osteosynthesis of long bones of lower limbs during time. Main goal is to suggest and verify the methodology for the evaluation of their wear, including a design concept for instrument and workpiece attachment.

\section{Methodology}

To carry out the experiment it was necessary to create a methodology that would simulate the conditions in real medical practice. That means it has to respect the pressure forces, speeds and feeds that can be achieved. Finally, we must achieve sufficient wear for pressure forces and torques to change $[2,3]$.

First, for a successful implementation, it was necessary to create a fixture that will be used to attach the instrument and workpiece in the loading machine. It had to be designed to sustain the measured torque and pressure force well. We designed two options that fulfil our requirements - axial and off-axis loading (see Fig. 1). 

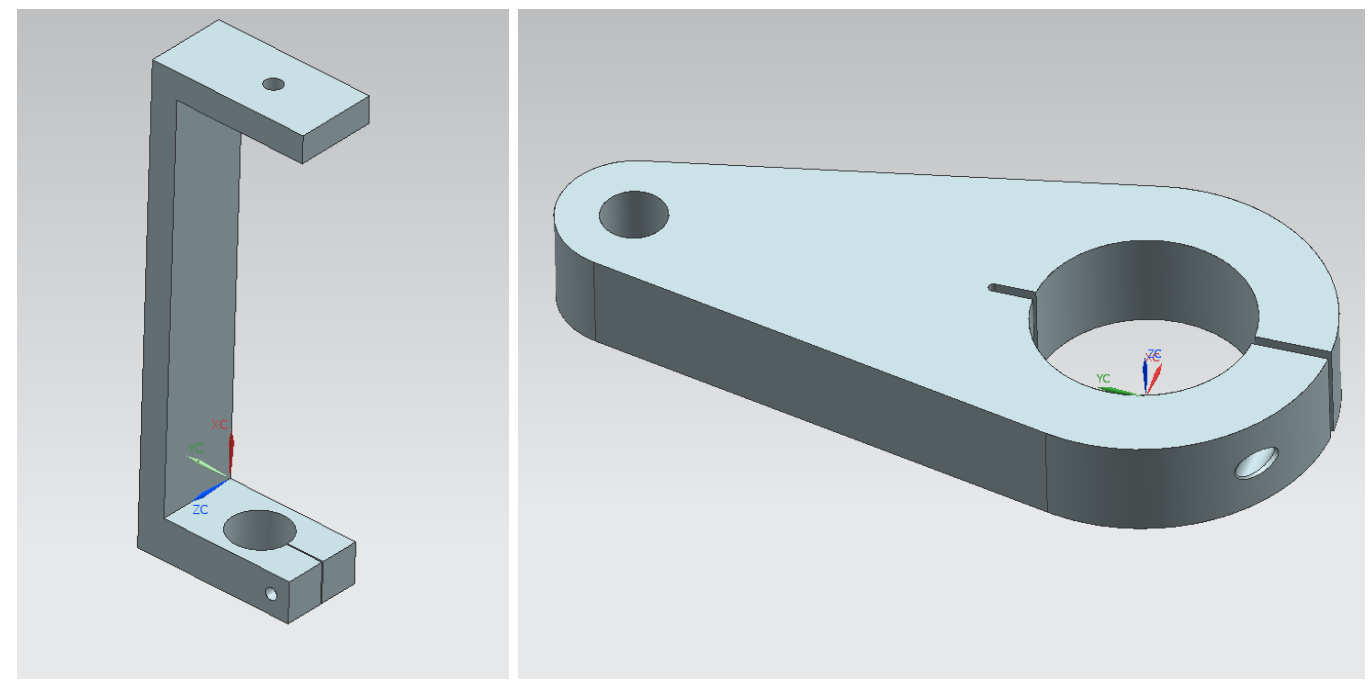

Fig. 1 Demonstration of power drill attachment - left axial, right off-axis

For both product variants, FEM simulations for both stress and strain after the load were performed for two selected materials - stainless steel and duralumin. After preliminary calculations, we have chosen duralumin due to the good rigidity and low weight.

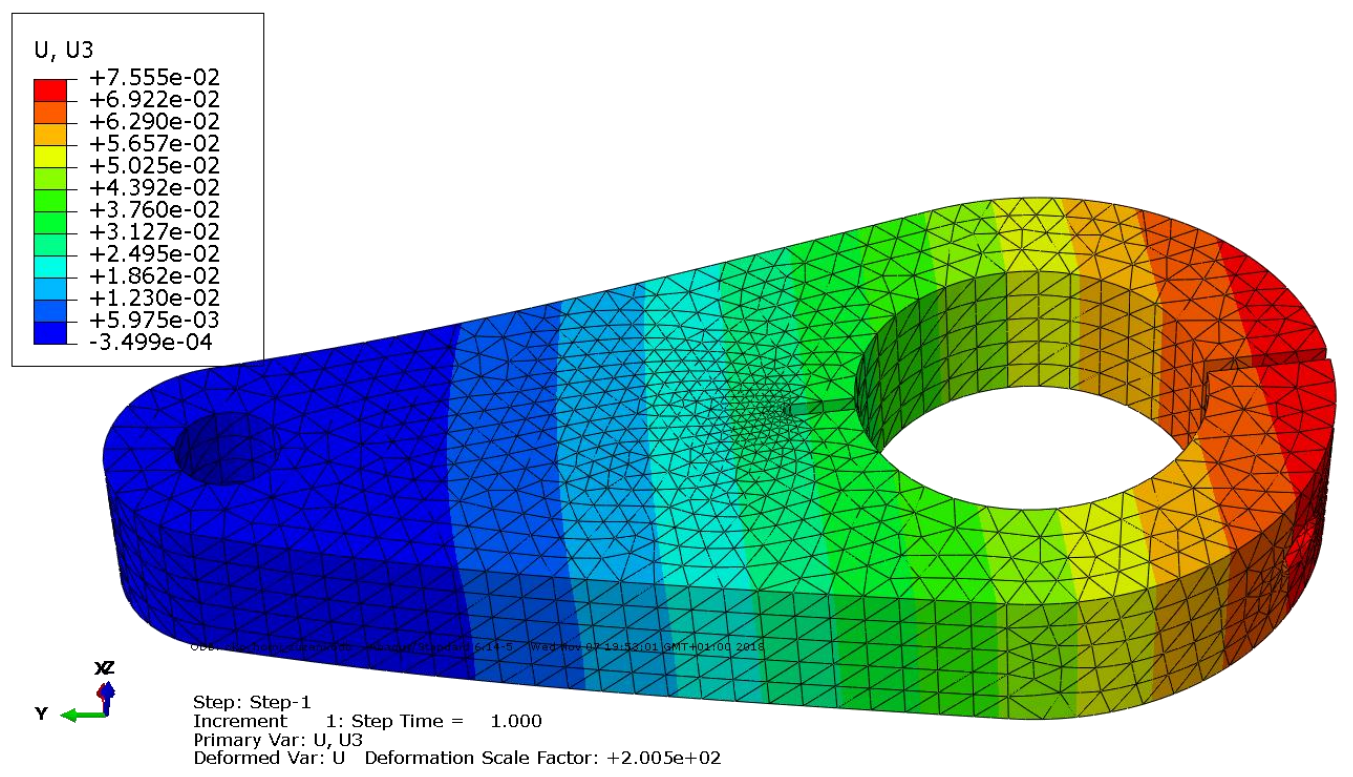

Fig. 2 FEM - graphical representation of the displacement in the vertical axis due to deformation

The numerical analysis shows that the off-axis solution achieves higher numbers in the maximum normal stress, however, this value is in the area affected by the clamping. Axial variant on the other hand has maximum is located in the corners. The decisive criterion in this case was a displacement localized in vertical axis that could unfavourably affects the measured parameters. This is due to the angle of rotation and misalignment of the clamped tool, which would cause uneven material removal. Following table (Tab. 1) summarizes the parameters obtained via FEM analysis. 
Tab. 1 Summary of parameters from FEM analysis

\begin{tabular}{c|c|c|c|c|c}
\hline \multirow{2}{*}{ Variant } & $\begin{array}{c}\text { Maximum } \\
\text { normal } \\
\text { stress }\end{array}$ & $\begin{array}{c}\text { Maximum } \\
\text { deflection }\end{array}$ & $\begin{array}{c}\text { Deflection in } \\
\text { drilling axis }\end{array}$ & Tool Angle & $\begin{array}{c}\text { Tool offset in } \\
\text { the location on } \\
\text { the workpiece }\end{array}$ \\
\cline { 2 - 6 } & $S[\mathrm{MPa}]$ & $u_{\max }[\mathrm{mm}]$ & $u_{\text {axis }}[\mathrm{mm}]$ & $\varphi\left[^{\circ}\right]$ & $x[\mathrm{~mm}]$ \\
\hline Axial & 6,5 & 0,242 & 0,130 & 0,075 & 0,209 \\
Off-axis & 23,4 & 0,008 & 0,050 & 0,029 & 0,080 \\
\hline
\end{tabular}

Based on the FEM analysis (see Fig. 2), we chose the more suitable off-axis drilling option.

Choice of cutting conditions and feeds were inspired by the available literature [2]. Our goal was to achieve the same circumferential speeds for all types of tested cutters, in different speed setups.

The tracked parameters chosen are the pressing force and torque that the operator must overcome when drilling (milling) the bone for nail implantation. We used three different statistical tests to evaluate these parameters before and after wear. Student $\mathrm{T}-$ test, MannWhitney $U$ - test and Kolmogor-Smirnov test [2, 4].

\section{$3 \quad$ Realization of drilling experiments}

We had 32 pieces of cutters with three different diameters -8 (see Fig. 3), 12 and 16,5 mm (groups A, B, C) for the experiment. We drilled a hole with a $6 \mathrm{~mm}$ drill, after clamping the power drill and workpiece. Since this is the initial setup of the methodology, we are using beech wood block approx. $90 \times 90 \times 200 \mathrm{~mm}$. Then in the same place, we continued the measured milling with the tested instrument (from the smallest to the largest) to a depth of $30 \mathrm{~mm}$ (see Fig. 4).

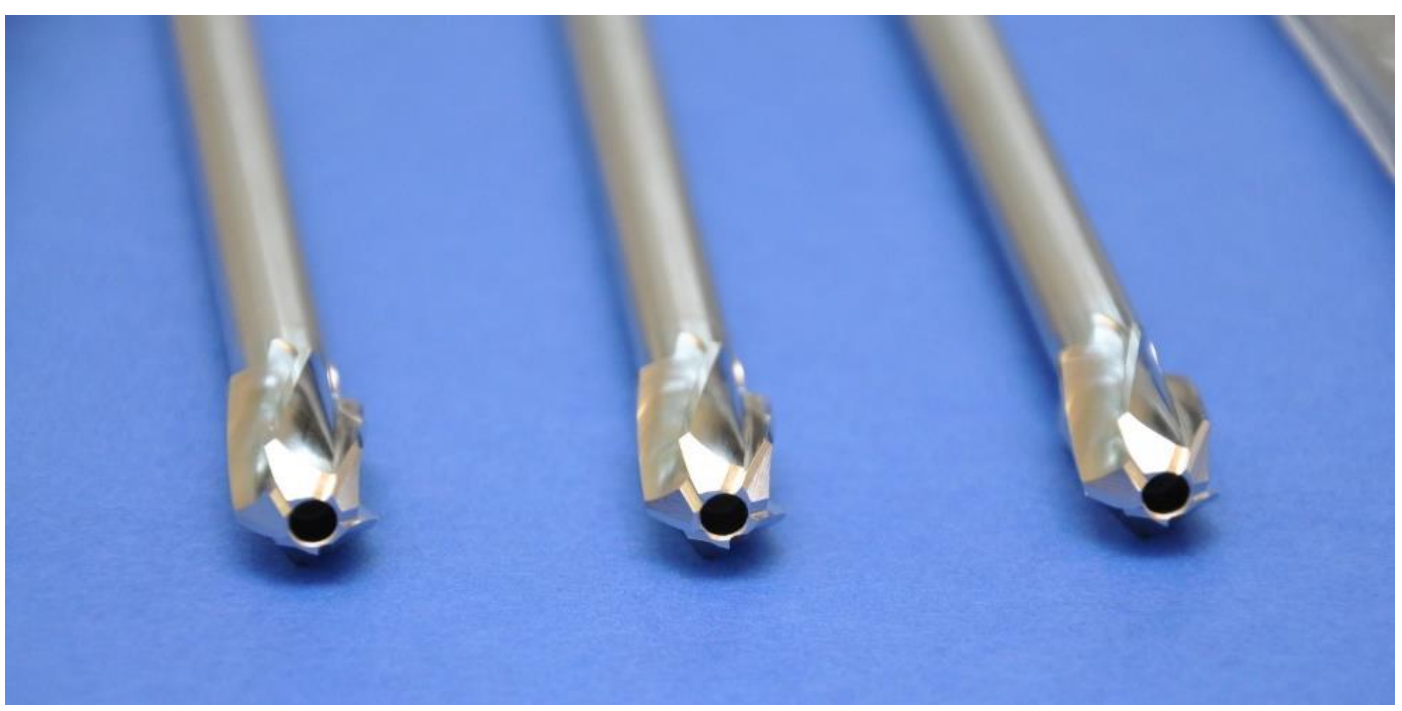

Fig. 3 Tested milling cutters 

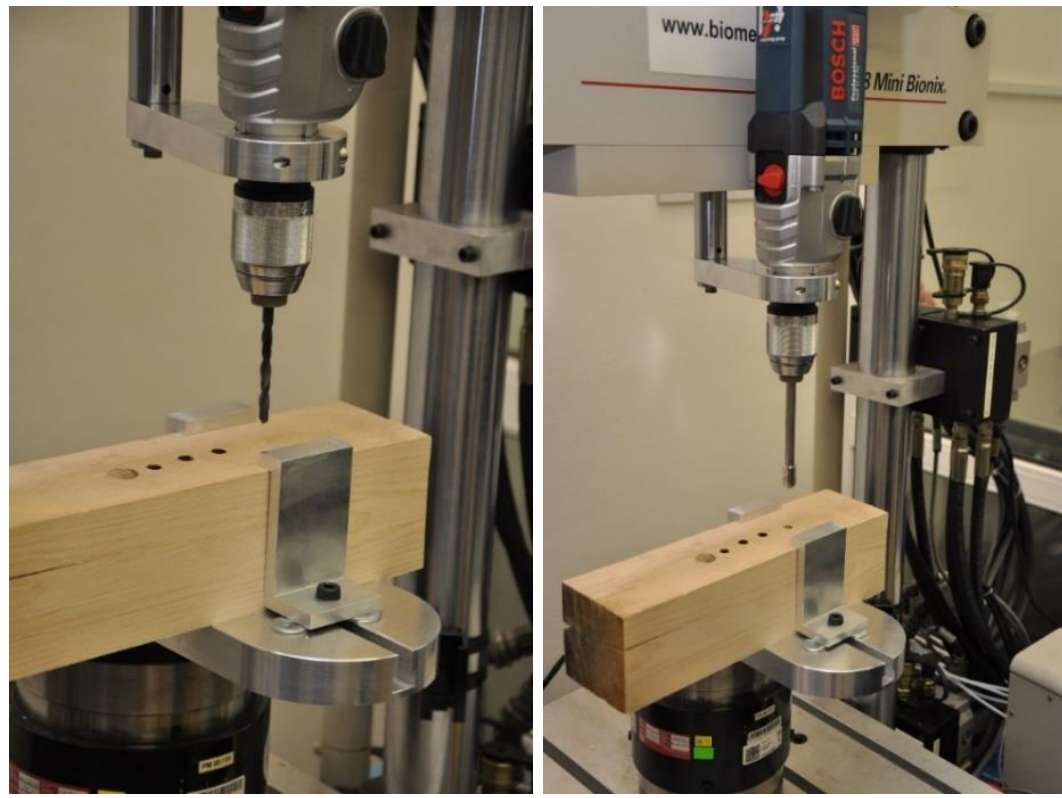

Fig. 4 Procedure preview - left drilling, right milling

We were using a contactless laser tachymeter to measure the speed, that we wanted to achieve, based on the chosen methodology. Chosen power drill allowed us to set the following speed values, i.e. $890 \mathrm{rpm}, 620 \mathrm{rpm}$ and $530 \mathrm{rpm}$ (for A, B and C mills) [5].

After the first measured load, we had to artificially wear the milling cutters. Wear was carried out by drilling into beech blocks, following the same procedure as for measurements, i.e. by the gradual use of each cutter (again first smaller and then larger diameter) in the same hole. On each cutter, we drilled 100 holes to the depth of the blade, i.e. about $30 \mathrm{~mm}$. We have repeated the measurement of the parameters on the worn milling cutters and performed statistical evaluation according to the chosen methodology $[2,3,6]$.

\section{Determined parameters and evaluation of conditions}

The time, displacement, pressure force and torque were recorded during loading. The collected data were plotted - the dependence of the pressure force on the feed (Fig. 5) and the dependence of the torque on the feed (Fig. 6).

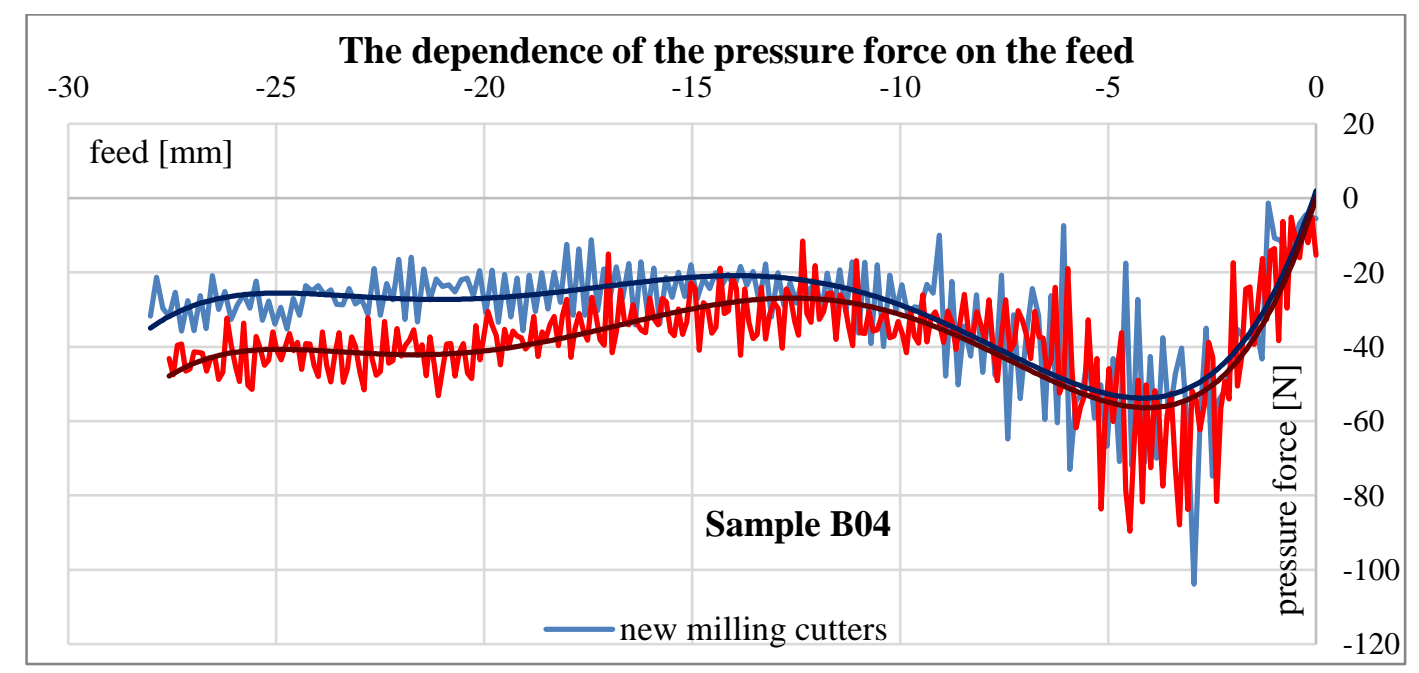

Fig. 5 Graph of the dependence of the pressure force on the feed - Sample B04

The above graph (Fig. 5) compares the dependence of the pressure force on the displacement for a representative sample of milling cutters (B04-12 mm diameter) before and after wear. 
At first sight the waveforms overlap. However, the worn-out tool achieves higher values in absolute value (this is a compressive force, i.e. negative values), as evidenced by the interleaved polynomial curves.

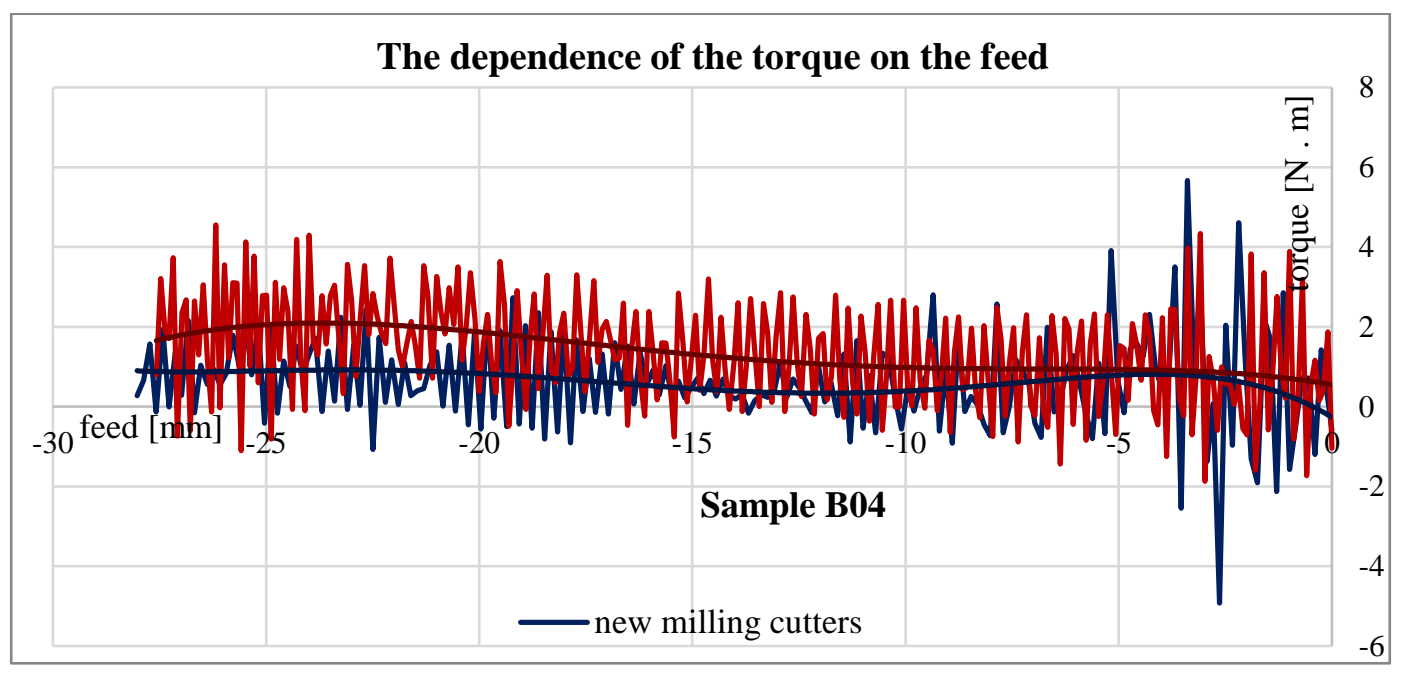

Fig. 6 Graph of the dependence of the torque on the feed - Sample B04

A torque comparison for one milling cutters (sample B04) before and after wear is shown in the graph above (Fig. 6). According to the interleaved polynomials, as well as during the pressure force, it can be seen that the worn milling cutters reach higher values.

We used medians to find out the specific differences between the measured data before and after wear for every force and torque in each group (A, B and C). We used the above-mentioned statistical tests to see if the difference in measured forces and torques is significant ( $\mathrm{T}$ - test, Mann-Whitney U - test, Kolmogorov-Smirnov test).

Tab. 2 Significance by individual statistical tests ${ }^{1}$

\begin{tabular}{c|ccc|ccc}
\hline \multirow{2}{*}{ Type of Test } & \multicolumn{3}{|c|}{ PRESSURE FORCE } & \multicolumn{3}{c}{ TORQUE } \\
\cline { 2 - 7 } & A & B & C & A & B & C \\
\hline T- TEST & 1 & 1 & 1 & 1 & 1 & 1 \\
\hline U- TEST & 0 & 1 & 1 & 1 & 1 & 1 \\
\hline K-S TEST & 0 & 1 & 1 & 1 & 1 & 1 \\
\hline
\end{tabular}

The table (Tab. 2) summarizes the significant changes between pre- and post-wear data. The Kolmogorov-Smirnov test is decisive. This means that only in the case of measurement of pressure forces of group A, we didn't prove any statistically significant changes.

Tab. 3 Overview of recorded median differences before and after wear ${ }^{2}$

\begin{tabular}{c|cc|cc|cc}
\hline Load & \multicolumn{2}{|c|}{ A } & \multicolumn{2}{c|}{ B } & \multicolumn{2}{c}{ C } \\
\hline $\begin{array}{c}\text { PRESSURE } \\
\text { FORCE }\end{array}$ & $1,65 \mathrm{~N}$ & $-6 \%$ & $-6,25 \mathrm{~N}$ & $23 \%$ & $-4,51 \mathrm{~N}$ & $15 \%$ \\
\hline TORQUE & $0,53 \mathrm{~N} \cdot \mathrm{m}$ & $90 \%$ & $0,51 \mathrm{~N} \cdot \mathrm{m}$ & $56 \%$ & $0,42 \mathrm{~N} \cdot \mathrm{m}$ & $25 \%$ \\
\hline
\end{tabular}

${ }^{1} 0=$ statistically insignificant change; 1 = statistically significant change

2 red text - a statistically insignificant difference before and after wear data

We have seen a $1,65 \mathrm{~N}$ decrease in median in group $\mathrm{A}$, although these changes were insignificant (Tab. 3). This extraordinary phenomenon was probably caused by the sensor 
range, too large for such small cutters. However, we seen an increase in torque, exactly by 0,53 $\mathrm{N} \cdot \mathrm{m}(90 \%)$. Milling cutters (in group B) achieved a significant increase in both monitored parameters, which represent increased wear resistance. The pressure force of these cutters was increased by $6,25 \mathrm{~N}(23 \%)$, torque was increased by $0,51 \mathrm{~N} \cdot \mathrm{m}(56 \%)$. For the largest tested tools, Group C milling cutters, we measured the pressure force after wear was 4,51 N (15\%) higher than new instrument. Torque was increased by $0,42 \mathrm{~N} \cdot \mathrm{m}(25 \%)$.

\section{CONCLUSION}

The proposed methodology and realized experiments showed significant wear of tested milling cutters. Pressure force measurements showed the greatest increase in resistance for $12 \mathrm{~mm}$ and $16,5 \mathrm{~mm}$ cutters. On the other hand, in the group of smallest tested $8 \mathrm{~mm}$ cutters, no significant changes were observed. In contrast, the increase in torque was recorded in all groups. From this finding it could be assumed that all milling cutters have a measurable increase resistance after wear. This leads to higher heating of the instrument and the drilled material, and therefore it is necessary to pay attention to the degree of wear of the used instruments by the operator.

The designed methodology is the first step in the next step of quantifying and measuring wear. It can be used for setting the decision criteria for regrinding or discarding the used milling instrument. Consequently, it could be used to calculate the tool usage interval for operations (what length of cavity can be drilled with one tool, without permanently affecting or even damaging the surrounding tissue). Further research promises to develop a new range of instrument that could counter this problem better.

\section{ACKNOWLEDGEMENTS}

This study was supported by the grant project awarded by the Ministry of Industry and Trade of the Czech Republic No. MPO FV30348.

\section{REFERENCES}

[1] Florencio-Silva, R., Sasso, G. R. S., Sasso-Cerri, E., Simores, M. J., Cerri, P. S. "Biology of Bone Tissue: Structure, Function, and Factors That Influence Bone Cells", BioMed Research International, pp. 1 - 17. 2015. DOI: 10.1155/2015/421746.

[2] Staroveski, T., Brezak, D., Toma Udiljak, T. "Drill wear monitoring in cortical bone drilling“", Medical Engineering \& Physics 37 (6), pp. 560 - 566, 2015. DOI: https://doi.org/10.1016/j.medengphy.2015.03.014

[3] Jantunen, E. "A summary of methods applied to tool condition monitoring in drilling", International Journal of Machine Tools and Manufacture 42 (9), pp. 997 - 1010, 2002. DOI: $10.1016 / \mathrm{S} 0890-6955(02) 00040-8$

[4] Anděl, J. "Matematická statistika. 2“, vyd. Praha: STNL, 1985.

[5] Zhu, L., Jen, T. - C., Yin, C. - L., Kong, X.-L., Yen, Y. - H. "Experimental verification of the feasibility and effectiveness of heat pipe cooling in drilling applications", Strojnícky časopis - Journal of Mechanical Engineering 62 (4), pp. 205 - 220, 2011.

[6] Keerthana, B., Vijaya Kumar, G., Anand Babu, K. "Effect of Minimum Quantity Lubrication on Surface Roughness and Temperature in Milling of EN31 Steel for Die Making“, Strojnícky časopis - Journal of Mechanical Engineering 69 (1), pp. 61 - 68, 2019. DOI: $10.2478 /$ scjme-2019-0005. 